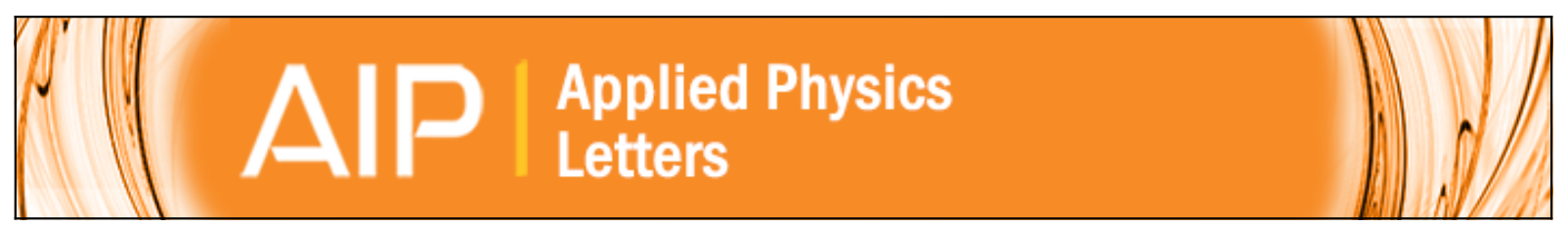

\title{
Quadruple-junction thin-film silicon-based solar cells with high open-circuit voltage
}

Fai Tong Si, Do Yun Kim, Rudi Santbergen, Hairen Tan, René A. C. M. M. van Swaaij, Arno H. M. Smets,

Olindo Isabella, and Miro Zeman

Citation: Applied Physics Letters 105, 063902 (2014); doi: 10.1063/1.4892890

View online: http://dx.doi.org/10.1063/1.4892890

View Table of Contents: http://scitation.aip.org/content/aip/journal/apl/105/6?ver=pdfcov

Published by the AIP Publishing

\section{Articles you may be interested in}

Multi-resonant silver nano-disk patterned thin film hydrogenated amorphous silicon solar cells for Staebler-

Wronski effect compensation

J. Appl. Phys. 116, 093103 (2014); 10.1063/1.4895099

Amorphous silicon oxide window layers for high-efficiency silicon heterojunction solar cells

J. Appl. Phys. 115, 024502 (2014); 10.1063/1.4861404

Analysis of sub-stoichiometric hydrogenated silicon oxide films for surface passivation of crystalline silicon solar cells

J. Appl. Phys. 112, 054905 (2012); 10.1063/1.4749415

Window layer with $p$ doped silicon oxide for high $\mathrm{V}$ oc thin-film silicon n-i-p solar cells

J. Appl. Phys. 110, 124511 (2011); 10.1063/1.3669389

Hydrogenated amorphous silicon oxide containing a microcrystalline silicon phase and usage as an intermediate reflector in thin-film silicon solar cells

J. Appl. Phys. 109, 113109 (2011); 10.1063/1.3592208

AIP $\left.\right|_{\text {Letters }} ^{\text {Applied Physics }}$

is pleased to announce Reuben Collins as its new Editor-in-Chief

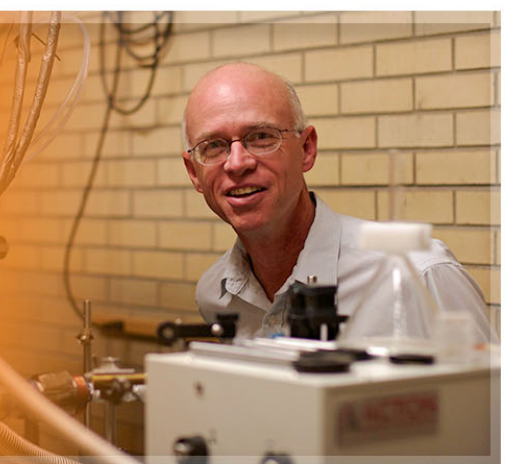




\title{
Quadruple-junction thin-film silicon-based solar cells with high open-circuit voltage
}

\author{
Fai Tong Si (施輝東), ${ }^{\text {a) }}$ Do Yun Kim, Rudi Santbergen, Hairen Tan, \\ René A. C. M. M. van Swaaij, Arno H. M. Smets, Olindo Isabella, and Miro Zeman \\ Laboratory of Photovoltaic Materials and Devices, Delft University of Technology, Delft 2628 CD, \\ The Netherlands
}

(Received 21 July 2014; accepted 31 July 2014; published online 13 August 2014)

\begin{abstract}
We have fabricated $\mathrm{a}_{-} \mathrm{SiO}_{\mathrm{x}}: \mathrm{H} / \mathrm{a}-\mathrm{Si}: \mathrm{H} / \mathrm{nc}-\mathrm{Si}: \mathrm{H} / \mathrm{nc}-\mathrm{Si}: \mathrm{H}$ quadruple-junction thin-film silicon-based solar cells (4J TFSSCs) to obtain high spectral utilization and high voltages. By processing the solar cells on micro-textured superstrates, extremely high open-circuit voltages for photovoltaic technology based on thin-film silicon alloys up to $2.91 \mathrm{~V}$ have been achieved. Optical simulations of quadruple-junction solar cells using an advanced in-house model are a crucial tool to effectively tackle the challenging task of current matching among the individual sub-cells in such devices. After optimizing the optical design of the device and the absorber thicknesses, an energy conversion efficiency of $11.4 \%$ has been achieved. The open-circuit voltage, short-circuit current density, and fill factor were $2.82 \mathrm{~V}, 5.49 \mathrm{~mA} / \mathrm{cm}^{2}$, and $73.9 \%$, respectively. Based on this demonstration, strategies for further development of highly efficient 4J TFSSCs are proposed. @ 2014 AIP Publishing LLC.

[http://dx.doi.org/10.1063/1.4892890]
\end{abstract}

Spectral mismatch is one of the major loss mechanisms for energy conversion in photovoltaic devices. When $E_{p h}>E_{g}$, where $E_{p h}$ is the energy of incident photon and $E_{g}$ is the band gap energy of absorber material, the energy of photon in excess of the band gap $\left(E_{p h}-E_{g}\right)$ is lost via thermalization and cannot be converted into electricity. When $E_{p h}<E_{g}$, the absorber is transparent to the photon, and the energy of the photon cannot be utilized as well. The effect of spectral mismatch on photovoltaic devices is evaluated with Shockley-Queisser limit. It concludes that the upper efficiency limit of solar cells consisting of a single semiconductor p-n junction is $33 \%$ for an absorber with an ideal band gap of $1.34 \mathrm{eV} .^{1,2}$ On one hand, the band gap of absorber should be high to reduce the thermalization loss, while on the other hand, it should be low to make use of a broader part of the solar spectrum. In order to overcome this problem, stacking multiple junctions in series is the most widely used approach. In this approach, photons are supposed to be absorbed in different junctions according to their energy and the band gap of the absorber material. Multi-junction solar cells promise smaller thermalization losses and, thus, a higher output voltage, as well as the utilization of long-wavelength photons. The performance of multi-junction cells depends on the band gaps of absorber materials. With absorbers having optimal band gaps, the corresponding efficiency limit is raised to $46 \%, 51 \%$, and $56 \%$ for double-, triple-, and quadruple-junction cells, respectively. ${ }^{2,3}$ Ideally, the more junctions with different band gaps are used, the higher efficiency can be achieved.

Thin-Film Silicon-based Solar Cells (TFSSCs) have been featuring the potential for low-cost and large-area manufacturing. Using raw materials which are highly abundant in the Earth's crust makes TFSSCs as a favorable source of

\footnotetext{
${ }^{\text {a) }}$ Author to whom correspondence should be addressed. Electronic address: f.t.si@tudelft.nl.
}

renewable energy. Improving its relatively low energy conversion efficiency is the main challenge to stay competitive with other photovoltaic technologies. Examining state-of-theart TFSSCs, the record efficiency increases from $11.0 \%$ at single-junction hydrogenated nanocrystalline silicon (nc-Si: $\mathrm{H})$ cells $\mathrm{s}^{4-6}$ to $12.6 \%$ at hydrogenated amorphous silicon (a-Si: $\mathrm{H}) / \mathrm{nc}-\mathrm{Si}$ :H tandem cells. ${ }^{7}$ Both record initial and stabilized efficiency of TFSSCs were achieved on triple-junction devices, which were $16.3 \%$ in a-Si:H/hydrogenated amorphous silicon germanium (a-SiGe:H)/nc-Si:H structure with shortcircuit current density $\left(\mathrm{J}_{\mathrm{SC}}\right)$ of $9.43 \mathrm{~mA} / \mathrm{cm}^{2}$ (Ref. 8) and $13.4 \%$ in a-Si:H/nc-Si:H/nc-Si:H structure with $\mathrm{J}_{\mathrm{SC}}$ of $9.52 \mathrm{~mA} / \mathrm{cm}^{2}, 9$ respectively. It is evident that the efficiency of TFSSCs could be improved by adding more junctions into a solar cell. Besides better spectral utilization, multi-junction TFSSCs benefit from mitigated light-induced degradation owing to thinner amorphous absorbers. From electrical point of view, the reduced operation current in such devices (e.g. half in a tandem, one-fourth in a quadruple-junction cell) comparing with single-junction cells leads to less parasitic electrical loss. A lower requirement of series resistance in the device means that the transparent conductive oxide (TCO) can be made thinner to reduce the parasitic optical absorption. ${ }^{10}$ Therefore, making quadruple-junction (4J) cells is considered a sensible option for further development of highly efficient TFSSCs. A theoretical study based on optical simulation $^{11}$ revealed that an initial efficiency of $19.8 \%$ can be achieved with a $4 \mathrm{~J}$ TFSSC with hydrogenated amorphous silicon oxide $\left(\mathrm{a}-\mathrm{SiO}_{\mathrm{x}}: \mathrm{H}\right)$, a-SiGe:H, nc-Si:H, and hydrogenated nanocrystalline silicon germanium (nc-SiGe:H) as the absorbers in the four component junctions. In that study, Lambertian scattering at internal interfaces was assumed and resulted in a $\mathrm{J}_{\mathrm{SC}}$ of $8.72 \mathrm{~mA} / \mathrm{cm}^{2}$. The simulation study demonstrated the potential of thin-film technology for being competitive with the mainstream silicon wafer-based or other thin-film photovoltaic technologies. So far, not many experimental results on 


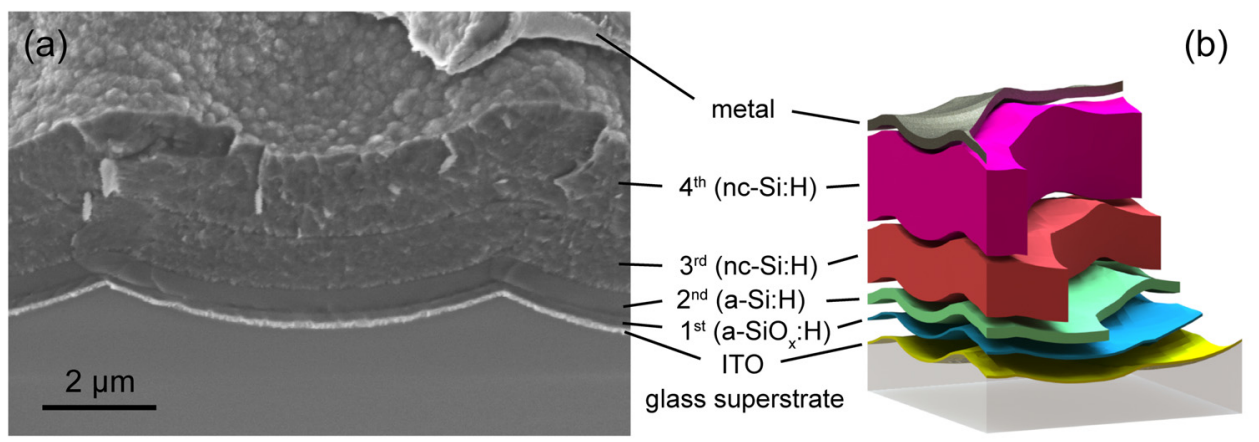

FIG. 1. (a) SEM image exhibiting the cross section of a $4 \mathrm{~J}$ cell in $p-i-n$ configuration with $\mathrm{a}_{-} \mathrm{SiO}_{\mathrm{x}}: \mathrm{H} / \mathrm{a}-\mathrm{Si}: \mathrm{H} / \mathrm{nc}-\mathrm{Si}$ : $\mathrm{H} / \mathrm{nc}-\mathrm{Si}: \mathrm{H}$ absorber layers on top of textured glass substrate. Division of the sub-cells is indicated. The image acquisition was performed at a tilted angle of $45^{\circ}$. (b) Simplified structure of the studied $4 \mathrm{~J}$ TFSSC.

4J TFSSCs have been reported since Yang et al. demonstrated in 1985 an a-Si:F:H/a-Si:F:H/a-Si:F:H/a-Si:Ge:F:H 4J cell with an efficiency of $11.0 \% .^{12}$ In that device, thick amorphous layers were used, and the device utilized a narrow range of the solar spectrum up to $900 \mathrm{~nm}$ that was limited by the use of a-Si:Ge:F:H absorber. In this work, we present experimental results of $4 \mathrm{~J}$ TFSSCs consisting of $\mathrm{a}-\mathrm{SiO}_{\mathrm{x}}: \mathrm{H} / \mathrm{a}-\mathrm{Si}: \mathrm{H} / \mathrm{nc}-\mathrm{Si}: \mathrm{H} /$ nc-Si:H absorbers with open-circuit voltage $\left(\mathrm{V}_{\mathrm{OC}}\right)$ up to $2.91 \mathrm{~V}$ and solar spectrum utilization up to $1100 \mathrm{~nm}$. Optical simulations were used to design the absorber thicknesses in such a way that light absorption is appropriately distributed in the four junctions. By optimizing the optical design of our $4 \mathrm{~J}$ cells, an initial efficiency of $11.4 \%$ has been achieved.

Our $4 \mathrm{~J}$ cells were initially fabricated by stacking an additional top sub-cell with $\mathrm{a}_{-} \mathrm{SiO}_{\mathrm{x}}: \mathrm{H}$ absorber ${ }^{13}$ on typical triple-junction a-Si:H/nc-Si:H/nc-Si:H cells. The band gap of $\mathrm{a}-\mathrm{SiO}_{\mathrm{x}}: \mathrm{H}(2.1 \mathrm{eV})$ is higher than that of a-Si:H $(1.8 \mathrm{eV})$. The shift towards a higher band gap offers a better spectral utilization in $\mathrm{a}-\mathrm{SiO}_{\mathrm{x}}: \mathrm{H} / \mathrm{a}-\mathrm{Si}: \mathrm{H} / \mathrm{nc}-\mathrm{Si}: \mathrm{H} / \mathrm{nc}-\mathrm{Si}: \mathrm{H}$ 4J cells. The properties of the intrinsic nc-Si:H absorbers in the 3rd and 4th sub-cells were not intentionally differentiated, so they may share the same band gap energy. In such configuration, two sub-cells with identical absorber material do not suppress the thermalization loss but provide a reasonable distribution of photo-generated carriers among all the sub-cells, since they are connected in series and the available currents should be well matched. Meanwhile, the absorber thickness in individual sub-cell is reduced that results in improved material quality and electrical carrier collection. Figure 1 shows the structure of the studied $4 \mathrm{~J}$ cells in a simplified sketch and a cross-sectional scanning electron microscope (SEM) image of a fabricated device.

The 4J TFSSCs were fabricated on textured glass substrates in $p-i-n$ configuration. The surface of the textured glass on which the layers were deposited resembled craterlike features with lateral correlation length around $6 \mu \mathrm{m}$ and aspect ratio of 0.1 . The micro-textured substrate was chosen to ease the defect control in this first demonstration of such device. The smooth morphology of substrate can avoid the formation of defective areas during nc-Si:H deposition so that guarantee high material quality. The glass texturing process has been reported elsewhere. ${ }^{14}$ 90-nm thick tin-doped indium oxide (ITO) was deposited as part of the front contact of the solar cells by radio-frequency magnetron sputtering. The $p-i-n$ junctions of the cells were deposited by radiofrequency (13.56 MHz) plasma-enhanced chemical vapor deposition (RF-PECVD), except for the intrinsic nc-Si:H absorber that was made using PECVD with a frequency of
40.64 MHz. A stack of $\mathrm{Ag} / \mathrm{Cr} / \mathrm{Al}$ with thickness of 300/30/ $500 \mathrm{~nm}$ was evaporated as back reflector and electrode, with a pattern defining the cell area $\left(4 \times 4 \mathrm{~mm}^{2}\right)$. After the depositions, edge isolation of the cells was performed by reactive ion etching of silicon and silicon alloys outside the cell areas. The fabrication was finished with a thermal annealing step at $170{ }^{\circ} \mathrm{C}$ for $2 \mathrm{~h}$. Relevant single-, double-, and triple-junction cells were co-deposited for obtaining information about the quality of the deposition process and the component subcells.

The fabricated cells were characterized by illuminated current-voltage (I-V) measurements with an AM $1.5 \mathrm{G}$ solar simulator to determine the $\mathrm{V}_{\mathrm{OC}}$ and fill factor (FF). The measured data in terms of voltage is presented in Table I. One can notice that the increase of $\mathrm{V}_{\mathrm{OC}}$ of a cell with increasing number of junctions is consistent with the $\mathrm{V}_{\mathrm{OC}}$ of corresponding single-junction cells. From $1.03 \mathrm{~V}$ for $\mathrm{a}_{-} \mathrm{SiO}_{\mathrm{x}}$ : $\mathrm{H}$ single-junction cell, the $\mathrm{V}_{\mathrm{OC}}$ was sequentially increased to $1.91 \mathrm{~V}, 2.41 \mathrm{~V}$, and, finally, $2.91 \mathrm{~V}$ for our $4 \mathrm{~J}$ TFSSC. Therefore, the $4 \mathrm{~J}$ cell functioned as expected from voltage point of view, showing that the absorber materials were of high quality in spite of the large thickness in the bottom cell. ${ }^{14}$ A fill factor up to $78 \%$ was obtained, but it should be noted that the value of FF can be affected by the level of current mismatch. ${ }^{15}$

External quantum efficiency (EQE) measurements with proper bias illumination were performed to investigate the spectral response of each sub-cell, as well as, to estimate the $\mathrm{J}_{\mathrm{SC}}$ of the whole $4 \mathrm{~J}$ device. For measuring the individual sub-cells, different combinations of LEDs were used to generate sufficient photocarriers in the remaining three subcells. The reflectance $(R)$ of the solar cell was also measured to determine the total absorption $(A=1-R)$ in the entire structure including parasitic optical losses in the supporting layers. In Figure 2, the colored symbols show the measured EQE of the four sub-cells of our first fabricated $4 \mathrm{~J}$ device.

TABLE I. Measured $\mathrm{V}_{\mathrm{OC}}$ of relevant TFSSCs. Column on the left shows the $\mathrm{V}_{\mathrm{OC}}$ of corresponding multi-junction cells starting with a-SiO $\mathrm{O}_{\mathrm{x}}: \mathrm{H}$ subcell. Values in parentheses indicate the increase in $\mathrm{V}_{\mathrm{OC}}$. Column on the right shows typical $\mathrm{V}_{\mathrm{OC}}$ of respective single-junction cells under $\mathrm{AM} 1.5 \mathrm{G}$ illumination.

\begin{tabular}{lcc}
\hline \hline & $V_{O C}(\mathrm{~V})$ & Component ${ }_{O C}(\mathrm{~V})$ \\
\hline $\mathrm{a}-\mathrm{SiO}_{\mathrm{x}}: \mathrm{H}$ & 1.03 & $1.03\left(\mathrm{a}-\mathrm{SiO}_{\mathrm{x}}: \mathrm{H}\right)$ \\
$\mathrm{a}-\mathrm{SiO}_{\mathrm{x}}: \mathrm{H} / \mathrm{a}-\mathrm{Si}: \mathrm{H}$ & $1.91(+0.88)$ & $0.89(\mathrm{a}-\mathrm{Si}: \mathrm{H})$ \\
$\mathrm{a}-\mathrm{SiO}_{\mathrm{x}}: \mathrm{H} / \mathrm{a}-\mathrm{Si}: \mathrm{H} / \mathrm{nc}-\mathrm{Si}: \mathrm{H}$ & $2.41(+0.50)$ & $0.53(\mathrm{nc}-\mathrm{Si}: \mathrm{H})$ \\
$\mathrm{a}-\mathrm{SiO}_{\mathrm{x}}: \mathrm{H} / \mathrm{a}-\mathrm{Si}: \mathrm{H} / \mathrm{nc}-\mathrm{Si}: \mathrm{H} / \mathrm{nc}-\mathrm{Si}: \mathrm{H}$ & $2.91(+0.50)$ & $0.53(\mathrm{nc}-\mathrm{Si}: \mathrm{H})$ \\
\hline \hline
\end{tabular}




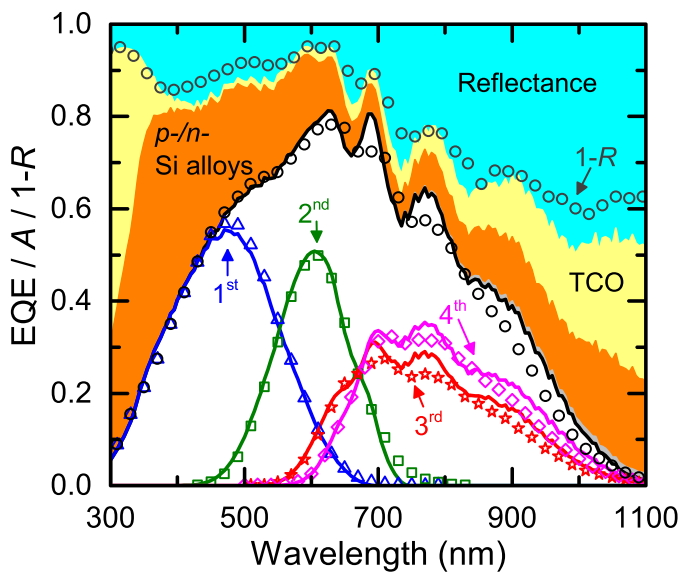

FIG. 2. Spectral response of a 4J TFSSC. Colored symbols are experimental EQE and reflectance, while solid lines show simulated absorption spectra of the four sub-cells in a same solar cell structure. Simulated reflectance and parasitic absorption are indicated by the area plot.

The photocurrent density which a sub-cell can potentially generate was calculated by integrating the respective EQE with the AM $1.5 \mathrm{G}$ spectrum, and the values are given in Table II. It can be seen that the light absorption, and thus the potential photocurrent density, is not evenly distributed over the component sub-cells. The net current density of multijunction solar cells is limited by the sub-cell delivering the smallest potential current density. The excess light absorption in other sub-cells cannot contribute to power generation.

Current mismatch is an essential problem in making highly efficient multi-junction TFSSC, and has a higher impact on the efficiency of solar cells consisting of more junctions because of their high voltage and low current density. Furthermore, current matching becomes more challenging for $4 \mathrm{~J}$ cells since the structure contains a large number of layers as well as textured interfaces and each of them can affect the optical environment of the others. It is impractical to experimentally optimize current matching from scratch because there are too many variables for optimization and the fabrication of $4 \mathrm{~J}$ TFSSCs at lab-scale is relatively timeconsuming. In order to facilitate the burdensome task of current matching, optical simulations have been used to estimate the absorption distribution in a solar cell. In the inhouse optical model GenPro $4,{ }^{16}$ simulation of scattering properties at a textured interface is treated either by ray tracing or by scalar scattering theory depending on feature size of the concerned morphology. The feature size of the textured glass is much larger than the wavelengths of interest; therefore, ray tracing approach was selected in our simulations. The light is regarded as coherent in most of the layers in the structure, except the glass substrate and the intrinsic

TABLE II. Implied/Measured photocurrent density of $4 \mathrm{~J}$ cells in $\mathrm{mA} / \mathrm{cm}^{2}$. Current densities in individual sub-cells and their sum as the total response in the absorbers are shown.

\begin{tabular}{lccccc}
\hline \hline & 1st & 2nd & 3rd & 4th & Total \\
\hline Simulated initial & 5.65 & 4.96 & 5.43 & 5.98 & 22.02 \\
Measured initial & 5.79 & 5.00 & 4.91 & 5.61 & 21.31 \\
Measured optimized & 5.49 & 5.99 & 6.16 & 6.09 & 23.73 \\
\hline \hline
\end{tabular}

nc-Si:H layers in the 3rd and 4th sub-cells, which are rather thick that the light does not exhibit interference effect. For the input parameters of simulation, atomic force microscopy was used to obtain morphological information of the textured substrate. The 3-dimensional topography was used to simulate the scattering properties of the interfaces by ray-tracing. Complex refractive indices of all involved materials were acquired with spectroscopic ellipsometry by analyzing respective layers deposited on flat glass. By assigning the materials, thicknesses, and interfaces to the simulated structure in the model, the absorption spectrum for every layer, as well as, the total reflectance of the device can be calculated. A simulation was carried out on a structure identical to the presented $4 \mathrm{~J}$ device, so that the effectiveness of the optical model can be evaluated by experimental results. The simulated spectral response of the four sub-cells shown in Figure 2 (solid lines) agrees reasonably well with the experimental results except for the discrepancy at long wavelengths. Interestingly, the clearly visible fluctuation of EQE between $600-900 \mathrm{~nm}$, the wavelength range within which the light is mainly absorbed in the 3rd and 4th sub-cells, actually originates from the effect of coherent propagation of light in the intrinsic a-Si:H layer in the 2 nd sub-cell. The discrepancy at long wavelengths may be ascribed to the less accurate characterization of materials' optical constants, considering that determining absorption coefficients by spectroscopic ellipsometry is very challenging for thin layers with low absorption. On the other hand, since the evolution of interface morphology depends on the deposition dynamics and is not perfectly conformal, ${ }^{17,18}$ the scattering properties will change with the morphology of the interface. Overall, the good agreement within a major part of the spectrum of interest confirms that this simulation approach is valid for our application, so it can be used for optimizing the design of $4 \mathrm{~J}$ solar cells, in particular, determining the thicknesses of absorber layers. Indeed, the simulated spectra also acted as a useful hint for choosing appropriate LEDs in the EQE measurements. According to the expected spectral response, the LEDs were selected to have low response in the measured sub-cell but can generate sufficient photocarriers in other sub-cells.

Optimization of 4J TFSSCs was then carried out, based on the materials available at our lab. The influence of intermediate reflector, $p$-layer of the top sub-cell, anti-reflective coating, and current matching has been taken into account. At first, $n$-type hydrogenated nanocrystalline silicon oxide $\left(\mathrm{nc}-\mathrm{SiO}_{\mathrm{x}}: \mathrm{H}\right)$ was used in the third and fourth sub-cells. It is a commonly used intermediate reflector for boosting the light absorption of upper sub-cells in multi-junction TFSSCs. ${ }^{819-21}$ However, it exhibits a broadband reflection which is not ideal for multi-junction cells. In this work, intermediate reflector was only used between the bottom subcells to avoid undesirable reflection losses of longwavelength light. Second, it can be seen in Figure 2 that the EQE of the first sub-cell does not exhibit a sharp onset due to significant parasitic absorption. Concerning parasitic optical losses, in addition to the front TCO, the $p$-layer in the first sub-cell is of major importance, because high-energy photons can be easily absorbed in these layers before reaching the first absorber layer. Tackling this problem, the deposition parameters of the $p$-layer were adjusted to make the 

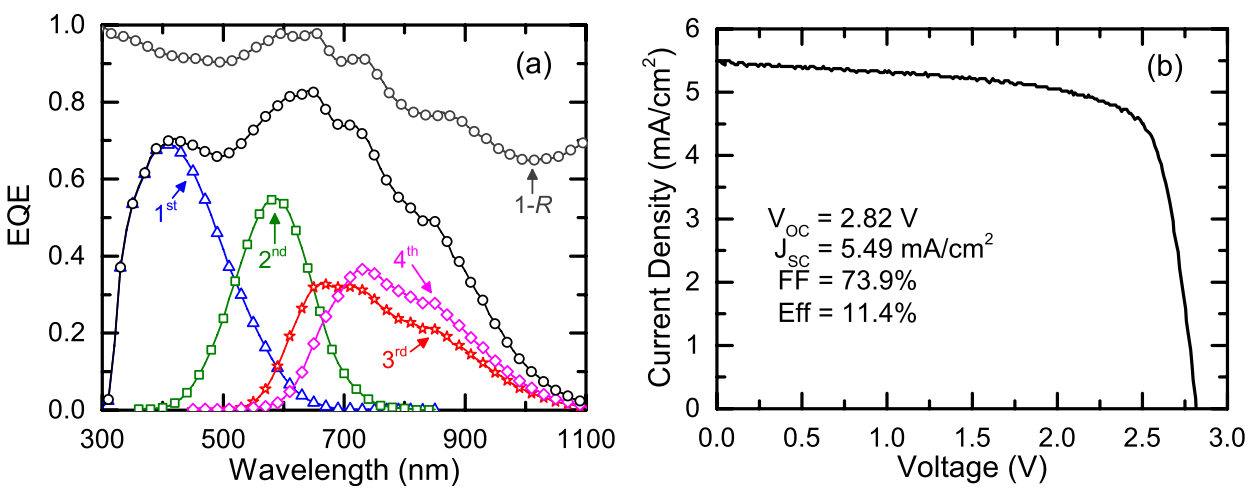

FIG. 3. (a) Measured spectral response and (b) measured J-V curve of an optimized 4J TFSSC. material more transparent. As a result, the improved response at the short wavelengths led to a gain in photocurrent density of $1 \mathrm{~mA} / \mathrm{cm}^{2}$, while the thickness of $\mathrm{a}-\mathrm{SiO}_{\mathrm{x}}: \mathrm{H}$ absorber could be reduced. Finally, a plastic foil functioning as a broadband anti-reflective layer was applied onto the front side of solar cells to enhance the in-coupling of incident photons into the device.

Once the configuration of $4 \mathrm{~J}$ TFSSCs with respect to the sequence of materials was decided, thickness determination of absorber layers was assisted by aforementioned optical simulations and fine-tuned by experimental examinations. The thicknesses of absorber layers from top to bottom were $70 \mathrm{~nm}, 380 \mathrm{~nm}, 1.9 \mu \mathrm{m}$, and $3.2 \mu \mathrm{m}$. Figure 3 shows the spectral response and illuminated $\mathrm{J}-\mathrm{V}$ curve of the optimized $4 \mathrm{~J}$ cell with better matched photocurrent densities and an improved optical design. From the EQE measurement, the $\mathrm{J}_{\mathrm{SC}}$ of the optimized cell was estimated to be $5.49 \mathrm{~mA} / \mathrm{cm}^{2}$. With $\mathrm{V}_{\mathrm{OC}}$ and FF of $2.82 \mathrm{~V}$ and $73.9 \%$, respectively, determined from illuminated I-V measurements, an initial efficiency of $11.4 \%$ has been achieved. The reduced $\mathrm{V}_{\mathrm{OC}}$ is due to the adaption of the $p$-layer.

Although the best initial efficiency of $11.4 \%$ achieved by the $4 \mathrm{~J}$ TFSSCs is less than the state-of-the-art tandem and triple-junction cells, it demonstrated high $\mathrm{V}_{\mathrm{OC}}$ and FF. The efficiency can be significantly improved by employing advanced materials in the cell. For instance, by replacing the front ITO with a high-mobility TCO material characterizing low free carrier absorption such as hydrogen-doped indium oxide $(\mathrm{IO}: \mathrm{H}){ }^{22}$ the absorption loss in the front TCO as well as the primary reflectance at long wavelengths can be reduced without compromising the electrical performance. Specifically, according to the simulations, the infrared absorption in front TCO can be decreased by an amount corresponding to a photocurrent density of $3 \mathrm{~mA} / \mathrm{cm}^{2}$. Similar adaption should also be applied to supporting $p$ - and $n$-layers. It can be seen in Figure 2 and Figure 3(a) that these supporting layers consume about $20 \%$ of the incident light in the range of $400-600 \mathrm{~nm}$ and a considerable amount in the infrared. On the other hand, the substrate morphology should be optimized to enhance the light scattering effect without sacrificing the quality of materials deposited subsequently. Deploying effectively-scattering substrate can raise the EQE in the long-wavelength while reducing the parasitic losses in the short-wavelength by efficiently absorbing the blue light in the top cell. Moreover, beyond the existing technology, one of the most important tasks is to develop high-performance narrowband intermediate reflectors, by which the blue light is reflected back to the upper sub-cells while the red light can be utilized in the bottom subcells. In this way, the thicknesses of amorphous absorbers in the upper sub-cells can be reduced, and a higher stabilized efficiency can be achieved in 4J TFSSCs. Last but not least, a low band gap absorber such as nc-SiGe: $\mathrm{H}^{23}$ should be introduced in the bottommost cell to absorb the low-energy photons, so that it can extend the spectral utilization of TFSSCs to a broader part of the solar spectrum. This absorber is expected to have high absorption coefficient at long wavelengths as well as high material quality to reduce the material consumption and guarantee satisfactory electrical performance.

To conclude, $\quad \mathrm{a}_{-\mathrm{SiO}}: \mathrm{H} / \mathrm{a}-\mathrm{Si}: \mathrm{H} / \mathrm{nc}-\mathrm{Si}: \mathrm{H} / \mathrm{nc}-\mathrm{Si}: \mathrm{H} \quad p-i-n$ quadruple-junction TFSSCs have been experimentally demonstrated with $\mathrm{V}_{\mathrm{OC}}$ higher than $2.82 \mathrm{~V}$. Current matching in the $4 \mathrm{~J}$ solar cells was facilitated by optical simulations to determine the optimal absorber thicknesses with minimum efforts at fabrication. Based on the available materials and light trapping scheme, the optical design of the solar-cell structure has been optimized. It resulted in a $\mathrm{J}_{\mathrm{SC}}$ of $5.49 \mathrm{~mA} / \mathrm{cm}^{2}$ and ultimately, an efficiency of $11.4 \%$. Strategies were pointed out for further improvement in the performance of 4J TFSSCs.

This work was carried out in the framework of the project "Stirring of Light!", funded by the Foundation for Fundamental Research on Matter (FOM), which is part of the Netherlands Organization for Scientific Research (NWO). The contribution of D.Y.K. was carried out in the framework of the FP7 project "Fast Track", funded by the EC under grant agreement no 283501. The work of H.T. and R.S. was funded by the Dutch STW-VIDI Grant-10782 of A.H.M.S.

${ }^{1}$ W. Shockley and H. J. Queisser, J. Appl. Phys. 32, 510 (1961).

${ }^{2}$ A. S. Brown and M. A. Green, Phys. E (Amsterdam, Neth.) 14, 96 (2002).

${ }^{3}$ A. De Vos, J. Phys. D: Appl. Phys. 13, 839 (1980).

${ }^{4}$ H. Sai, K. Saito, N. Hozuki, and M. Kondo, Appl. Phys. Lett. 102, 053509 (2013).

${ }^{5}$ H. Sai, T. Koida, T. Matsui, I. Yoshida, K. Saito, and M. Kondo, Appl. Phys. Express 6, 104101 (2013).

${ }^{6} \mathrm{H}$. Sai, T. Matsui, M. Kondo, and I. Yoshida, in 2014 IEEE 40th Photovoltaics Specialists Conference (IEEE, Denver, 2014).

${ }^{7}$ M. Boccard, M. Despeisse, J. Escarre, X. Niquille, G. Bugnon, S. Hänni, M. Bonnet-Eymard, F. Meillaud, and C. Ballif, in 2014 IEEE 40th Photovoltaics Specialists Conference (IEEE, Denver, 2014).

${ }^{8}$ B. Yan, G. Yue, L. Sivec, J. Yang, S. Guha, and C.-S. Jiang, Appl. Phys. Lett. 99, 113512 (2011).

${ }^{9}$ S. Kim, J.-W. Chung, H. Lee, J. Park, Y. Heo, and H.-M. Lee, Sol. Energy Mater. Sol. Cells 119, 26 (2013).

${ }^{10}$ C. Battaglia, J. Escarré, K. Söderström, L. Erni, L. Ding, G. Bugnon, A. Billet, M. Boccard, L. Barraud, S. De Wolf, F.-J. Haug, M. Despeisse, and C. Ballif, Nano Lett. 11, 661 (2011). 
${ }^{11}$ O. Isabella, A. H. M. Smets, and M. Zeman, "Thin-film silicon-based quadruple junction solar cells approaching 20\% conversion efficiency," Sol. Energy Mater. Sol. Cells (in press).

12 J. Yang, R. Ross, R. Mohr, and J. P. Fournier, in 1985 IEEE 18th Photovoltaics Specialists Conference (IEEE, Las Vegas, 1985), pp. 1519-1522.

${ }^{13}$ D. Y. Kim, E. Guijt, R. A. C. M. M. van Swaaij, and M. Zeman, "Development of a-SiOx:H solar cells with very high $\operatorname{Voc} \times$ FF product," Prog. Photovoltaics (submitted).

${ }^{14}$ H. Tan, E. Psomadaki, O. Isabella, M. Fischer, P. Babal, R. Vasudevan, M. Zeman, and A. H. M. Smets, Appl. Phys. Lett. 103, 173905 (2013).

${ }^{15}$ M. Meusel, R. Adelhelm, F. Dimroth, A. W. Bett, and W. Warta, Prog. Photovoltaics 10, 243 (2002).

${ }^{16}$ M. Zeman, O. Isabella, S. Solntsev, and K. Jäger, Sol. Energy Mater. Sol. Cells 119, 94 (2013).
${ }^{17}$ S. Solntsev, O. Isabella, D. Caratelli, and M. Zeman, IEEE J. Photovoltaics 3, 46 (2013).

${ }^{18}$ M. Sever, B. Lipovšek, J. Krč, A. Cõampa, G. S. Plaza, F.-J. Haug, M. Duchamp, W. Soppe, and M. Topicõ, Sol. Energy Mater. Sol. Cells 119, 59 (2013).

${ }^{19}$ P. Buehlmann, J. Bailat, D. Dominé, A. Billet, F. Meillaud, A. Feltrin, and C. Ballif, Appl. Phys. Lett. 91, 143505 (2007).

${ }^{20}$ A. Lambertz, T. Grundler, and F. Finger, J. Appl. Phys. 109, 113109 (2011).

${ }^{21}$ P. D. Veneri, L. V. Mercaldo, and I. Usatii, Appl. Phys. Lett. 97, 023512 (2010).

${ }^{22}$ T. Koida, H. Fujiwara, and M. Kondo, Appl. Phys. Express 1, 041501 (2008).

${ }^{23}$ T. Matsui, C.-W. Chang, K. Mizuno, Y. Takeuchi, and M. Kondo, Jpn. J. Appl. Phys. 51, 091302 (2012). 